\title{
A Review of State-of-the-Art on Wireless Body Area Networks
}

\author{
Fatemeh Rismanian Yazdi ${ }^{1}$ \\ ${ }^{1}$ Department of Computer \\ Engineering, Tehran North Branch, \\ Islamic Azad University, Tehran, \\ Iran
}

\author{
Mehdi Hosseinzadeh ${ }^{2,3}$ \\ ${ }^{2}$ Iran University of Medical Sciences, \\ Tehran, Iran \\ ${ }^{3}$ Computer Science, University of \\ Human Development, Sulaimaniyah, \\ Iraq
}

\author{
Sam Jabbehdari ${ }^{4}$ \\ ${ }^{4}$ Department of Computer \\ Engineering, Tehran North Branch, \\ Islamic Azad University, Tehran, \\ Iran
}

\begin{abstract}
During the last few years, Wireless Body Area Networks (WBANs) have emerged into many application domains, such as medicine, sport, entertainments, military, and monitoring. This emerging networking technology can be used for e-health monitoring. In this paper, we review the literature and investigate the challenges in the development architecture of WBANs. Then, we classified the challenges of WBANs that need to be addressed for their development. Moreover, we investigate the various diseases and healthcare systems and current state-ofthe-art of applications and mainly focus on the remote monitoring for elderly and chronically diseases patients. Finally, relevant research issues and future development are discussed.
\end{abstract}

Keywords-Wireless body area networks; review; challenges; applications; architecture; radio technologies; telemedicine

\section{INTRODUCTION}

As time goes on, communication technologies have started the gap toward a pervasive world. Because of, MP3 players and mobile phones are portable devices; people normally carry these devices around their bodies. In 1995, Zimmerman examined how these electronic devices operate near or inside the human body. He used the term PAN, personal wireless network as a communication channel for communication within the body. Later, around 2001, PAN term has been changed to encompass communications and implantable use of devices around or inside the body to the physical network BAN [1]. Body sensor networks are called, BSN. The Physical wireless network is a mono-purpose wireless sensor network that combines different wireless networks and devices to able remote monitoring. BAN devices may be embedded in the body or may be mounted on the body or in a fixed position on the wearable technology or may be placed in mobile devices that people can carry in different situations, in clothing, pocket, hand or different bags [2]. Gateway devices are used to connect wearable devices to the Internet through the human body. As a result, medical professionals can use online patient data from the patient's own Internet access [3].

One of the WBANs applications is the medical environment in which the situation of a large number of patients should be controlled permanently or in real-time. To create WBANs, several tiny wireless sensors are in strategic areas in or around the patient's body. Currently, wireless monitoring of physiological signals is one of the basic needs to deploy complete WSNs in health systems. The main purpose of the WABNs is to provide biological feedback information and consistently control the body's health parameters such as body temperature, blood glucose, heart rate, body movement, electrocardiogram (ECG), electroencephalogram (EEG), electromyography (EMG), galvanic skin response (GSR), photoplethysmography (PPG), and arterial blood pressure and heart with a simple and efficient way. Because of health care costs are increasing and the world population ageing, human health monitoring is one of the important issues [4], [5].

The rest of the paper is structured around the following sections: different architecture of WBANs and characteristics of communication and the position of WBANs presented in Section 2. In Section 3, medical and non-medical application and different device of WBANs are evaluated. Design challenges and requirements and open issue are discussed in Section 4. Communication standard and radio technologies present in Section 5. Telemedicine and diverse disease that monitor by WBANs are discussed in Section 6. Finally, conclusion and future direction are provided in the last section.

\section{WBANS ARCHITECTURE}

WBANs were classified with intelligent nodes based on implementing within the body as follows: In the body or implantable sensors - these nodes implanted in the patient's body, inside the body tissue or underneath the skin. On the body or wearable sensors - these nodes placed the surface of the patient body or two centimeters away from it [6]. Placed it around the body or surface sensors - these nodes are external of the body rather than five meters away from a patient's body [7].

These nodes are continually monitoring patient vital information and usually utilize wireless communication to join a master node. The first, master node accumulates data from all the other nodes in the network and then directs the information to the medical devices. According to the received data and patient's specifications, the medical team can do proper medical practice. Moreover, this system can provide records of vital sign of the patient. In general, these sensors measured the precise parameter of the patient and the actor sensor action based on the information gained from sensors. 
In another classification, the sensors in each WBANs are divided into two categories based on the kind of signal measurements [7]. The first type is gathering with variable signal continuous which needs to real-time signal processing such as, electrocardiograms graph [8] sensors and accelerometer [9]. The second type is a collection of discrete variable time signal that they are not immediately for instance, Pressure sensors [10], and respiratory tract sensor [11]. In Table 1, the summary of the general characteristics of WBANs is provided [2].

These nodes can have diverse topologies including the star, mesh, and tree topologies. Nevertheless, the most standard topology is the star in which node in the center of the star being placed at a location and the other nodes are connected to a central master node. Based on the application, sometimes various nodes connect to a central master node to merge the process and transfer information. Some of the parts of the human body movements are pondering the relative to each other and this process should be considered until deploying nodes in the body. In Fig. 1 explains an example of nodes based on the human body. Nodes to transmit sound and images must be cautiously established with attention to sensitive nerve in the head. In addition, the sensitivity of the SAR (Specific Absorption Rate) eye should be regarded. The nodes located in the torso and head towards each other will not move very much. Nevertheless, the nodes located in boundaries for example legs, arms, torso and head may move toward each other more [12].

In Table 2 is explained possible communication between nodes in the body [13]. These nodes have very low processing power and are able to produce energy for the whole body in the body and on the body. Nevertheless, these nodes in close proximity to or inside the human body and thus position SAR can be a slightly larger, if all power is available for a small volume of data. Thus, localization of SAR in the body must be at least [14].

Another architecture for WBANs in medical and nonmedical application are designed. According to demand, it can be used in the emergency event or normal traffic. Upon demand to attain special information, traffic is started by master node and is the maximum goal for diagnostic recommendations. These are divided in two interconnected (in case of operation) and discrete (when information is required from time to time). Emergency traffic management is started by starting node when more than a predefined threshold exists and must be replaced in less than a second. This kind of traffic is not created at regular intervals and is quite unpredictable [14].

Normal traffic data is requested in a normal condition with no critical time for events. This consists of the general health of patients and their treatments for many diseases; for example, gastrointestinal, neurological disorders, cancer, rehabilitation, disability, heart diseases and more. Normal data are gathered, and the master node does the processing. Depending on the application requirements, the master node may include a raiser radio circuit to transfer of critical life emergency and an additional circuit to connect multiple physical layers. More master nodes are connected to critical telemedicine and medical server for the appropriate recommendations [15].

TABLE I. GENERAL CHARACTERISTICS OF WBANS

\begin{tabular}{|l|l|}
\hline Attribute & Value \\
\hline Network size & Max 100 devices \\
\hline Network density & $2-4 \mathrm{Nets} / \mathrm{m}^{2}$ \\
\hline Network Setup time & $<1 \mathrm{Sec} /$ device \\
\hline Power consumption & $<1 \mathrm{~m} \mathrm{~W} / \mathrm{Mbps}$ \\
\hline Startup time & $<100 \mathrm{~ns}$ \\
\hline Latency (end to end) & $10 \mathrm{~ms}$ \\
\hline Distance & 2 meter stander 5meter special case \\
\hline
\end{tabular}

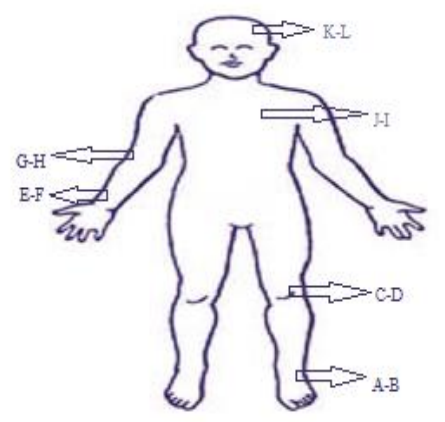

Fig. 1. Description node links on the body.

TABLE II. DISTRIBUTED WBANS ON BODY

\begin{tabular}{|l|l|}
\hline Link & Description \\
\hline A-B & Through the ankle \\
\hline C-D & Through the thigh \\
\hline E-F & Through the hand \\
\hline G-H & Through the wrist \\
\hline I-J & Torso, front to back \\
\hline K-L & Left ear to right ear \\
\hline
\end{tabular}

WBANs in many ways are similar to the wireless network, but the differences between the two can be seen. Scalability in WBANs limited in the human body, but in WSN can monitor the environment in the wide area covered. Node density also is numerous in WBANs while in WSNs is few and limits. Security and privacy level and authentication of a node and real-time communication among most important issue in WBANs while in WSNs no attention to support them. Usually in the WBANs nodes perform multi-tasks, but in WSNs is purpose single.

In addition, data rate, mobility, network topology, node size between two networks is diverse result in different architect to design and implementation. Most importantly, energy source and high reliability and low delay are very critical for WBANs because data mostly consist of medical information and can be as a life threat for patients [16], [17]. Thus, WBANs have several advantages rather than WSNs such as flexibility, effectiveness and cost-effective. Table 3 
shows the differences between wireless body area networks and wireless sensor networks.

TABLE III. DIFFERENCES BETWEEN WIRELESS BODY AREA NETWORKS AND WIRELESS SENSOR NETWORKS

\begin{tabular}{|l|l|l|}
\hline Issues & Wireless Body Area Network & $\begin{array}{l}\text { Wireless Sensor } \\
\text { Network }\end{array}$ \\
\hline Node Size & Small is essential & $\begin{array}{l}\text { Small is preferred, but } \\
\text { not important }\end{array}$ \\
\hline Scale & Human body (centimeters/m) & $\begin{array}{l}\text { Monitored Environment } \\
\text { (meters/ km) }\end{array}$ \\
\hline Node Tasks & Node performs multiple tasks & $\begin{array}{l}\text { Node performs a special } \\
\text { task }\end{array}$ \\
\hline $\begin{array}{l}\text { Network } \\
\text { Topology }\end{array}$ & $\begin{array}{l}\text { More variable because of body } \\
\text { movement }\end{array}$ & $\begin{array}{l}\text { Very likely to be fixed } \\
\text { or static }\end{array}$ \\
\hline $\begin{array}{l}\text { Node } \\
\text { Number }\end{array}$ & Fewer, limited in space & $\begin{array}{l}\text { Many redundant nodes } \\
\text { for wide area coverage }\end{array}$ \\
\hline $\begin{array}{l}\text { Energy- } \\
\text { Scavenging } \\
\text { Source }\end{array}$ & Most likely motion and thermal & $\begin{array}{l}\text { Most likely solar and } \\
\text { wind power }\end{array}$ \\
\hline $\begin{array}{l}\text { Node } \\
\text { Lifetime }\end{array}$ & $\begin{array}{l}\text { Several years/months, smaller } \\
\text { battery capacity }\end{array}$ & Several years/months \\
\hline $\begin{array}{l}\text { Node } \\
\text { Replacement }\end{array}$ & $\begin{array}{l}\text { Replacement of implanted nodes } \\
\text { difficult }\end{array}$ & $\begin{array}{l}\text { Likely to be lower, energy } \\
\text { supply more difficult }\end{array}$ \\
\hline $\begin{array}{l}\text { Power } \\
\text { Demand }\end{array}$ & IEEE 802.15.6 & $\begin{array}{l}\text { Likely to be large, } \\
\text { energy supply easier }\end{array}$ \\
\hline $\begin{array}{l}\text { Wireless } \\
\text { Technology } \\
\text { Result } \\
\text { Accuracy }\end{array}$ & $\begin{array}{l}\text { Through node accuracy and } \\
\text { robustness } \\
\text { Lecurity }\end{array}$ & $\begin{array}{l}\text { Highetooth, ZigBee, } \\
\text { GPRS, WLAN } \\
\text { Through node } \\
\text { redundancy }\end{array}$ \\
\hline $\begin{array}{l}\text { Biocompatibi } \\
\text { lity }\end{array}$ & $\begin{array}{l}\text { A must for implants and some } \\
\text { external sensors }\end{array}$ & $\begin{array}{l}\text { Not a consideration in } \\
\text { most applications }\end{array}$ \\
\hline
\end{tabular}

\section{APPLICATION AND DIFFERENT TYPE OF DEVICES}

The human body sensor network has a lot of potential for a variety of applications including remote medical diagnosis, interactive games and military applications. Table 4 lists some of the applications of the sensor in the body and on the body. Applications inside the body include the supervision and program changes for regulating heart rate and substantial heart implant in the body, the limb movement, and restoration of bladder function control. Medical applications in the body sensors include monitoring of ECG, blood pressure, temperature, and respiration. On-body sensors communicate between a getaway device and sensors. In addition, the body of non-medical applications includes monitoring of forgotten things, creating social networks and assesses soldier's battle. Some of the human body sensor network applications are discussed below [13], [15].

According to the type of application, data rate information and ranging from transferring data are different. Data can also be sent in similarly stream and the higher rates posted during the explosion. The reliability of the data transmission for the guarantee of the correct data is received from health-care professionals in term of bit error rate (BER) for the number of lost packets [17]; for medical devices, the reliability is based on the speed of the data. Low data rate can be a high BER $\left(10^{-}\right.$ $\left.{ }^{4}\right)$ while devices with higher data rates require a lower BER $\left(10^{-10}\right)$ can be gained [16]. Energy consumption is critical issue in the design for improving the lifetime of battery WBANs. Energy is used for sensing, communication, and processing data. Usually, the available energy for nodes is limited. Energy consumption based on utilities, shape, and position and the rate of transfer data is different. Generally, providing Qos in management of medical applications, especially in healthcare application is important [16].

Additional demands have increased fast exponential cost of health care and medical interventions for innovative solutions for remote health monitoring as a body sensor network [12]. The result in WBANs extends a wide area in medical application.

In medical application for healthcare is prevention, diagnosis, treatment of diseases and other physical and mental of people activities. Also, for animal healthcare with different sensors such as accelerometer, GPS, Bluetooth, temperature, humidity, wind sensor monitoring for realizing the disease, for example, respiratory, gastrointestinal, metabolic [18], [19] that prevent of these disease could be helpful for massive financial losses in the animal agriculture industry. Medical application has many classifications for monitoring general healthcare, disability assistance, infant healthcare, pregnant women, elderly monitoring. In neonatal monitor the smart jacket or wrist band with wearable sensors and smart textile. In [20] author has suggested design of continuing vital health monitoring. There are different sensors, such as ECG with conductive textiles and phototherapy with skin sensors and temperature sensor, pulse rate sensors.

Also, the system consists of special hardware, namely, microphone to record voice, memory and processors for analyzing information and Bluetooth for transferring information. In [21] the author suggested a wrist band for the baby named Kims. Wrist sensor monitors vital parameters of infant and processing information for early detection of infectious diseases and treatments. Wristband consist of various types of sensors for the instance microphone for record audio signals and then with processing signal recognize health sings for example cry, sneeze, vomit and cough. Then processing with coding scheme and compare with original signs for awareness of disease to beginning the treatment.

In non-medical application can be classified in entertainment such as interactive games, dance lessons, microphones, shopping and cameras and advanced computer and so on [22], [23] and training the sports for instance golf, football, and cricket where athletes sensors connected to the body and move them to record and review their training and monitoring and self-assessment and better adjustment to professional athletes plan and rehabilitation and motion capture [24]. Smartphone and wearable watches are being connected to BANs for gaining physiological parameters, for example heart rate, acceleration, gait length by distance measurement, pace, burned calories and elapsed time.

Military and security applications consisting of the camera, biometric sensors, GPS are supported by body sensor 
networks, particularly for the control and monitor the battlefield where the sensors are located with soldiers, move to track, monitor their health, and detect the existence of toxic substances in the air and that life-treating people [13]. Sleep disorders are the significant issue in daily lives. Thus, sleep monitoring attracted many researchers in these years. Moreover, it is widely used in varied medical application and implant sensors, for example cardiovascular diseases, diabetes, cancer and remote control sensors such as telemedicine system, patient monitoring. New BANs applications suggested in [25] for example, identify frostbites, assist blind swimmers that support the special disease. Fig. 3 summarizes categories of WBANs application.

A taxonomy of the device represents for monitoring patients as follow: Node wireless sensor is a device that collects and responses to physical stimuli and makes the process on data report data for wireless sensor. This device includes hardware components, such as sensors, processing unit, a processor, memory and a transmitter or receiver [26]. A Wireless Driving node is a device that the data received from the sensor or through user interaction works. The sensor actuator components consist of hardware drivers (medical hardware, for instance a drug-delivery system) a processing unit, processor, memory and a receiver or transmitter [2].

Wireless personal devices (PD) is a device that all information gained by the sensors and actuators to gather user information through an external gate driver or a page Show LEDS on it. The components of this device consist of a processing unit, processor, memory and a transmitter and receiver [16]. This device is called Body Control Unit (BCU), body gateway or sink. In some design, a Personal Digital Assistant (PDA) or smart phone is used [27]. Many diver's kinds of sensors and actuators are used in WBANs. The significant target of all these devices can be found in health applications. The number of nodes in WBANs depends on the abilities and the nature of the network. Usually, the number of nodes is in the range of 20-50 [28], [29]. There are challenging issues in the design and implementation of WBANs. Following are mentioned some of the issues.

\section{WBANS DESIGN CHALLENGES AND OPEN ISSUE}

In this section, we present the main challenges of WBANs. There are numerous challenges such as reliability, security, size, latency, privacy, availability, capacity constraints, confidentiality, data speed, bandwidth, mobility, the quality of service requirements, transmission range, and so on [30]. Proficient communication is as ease of deployment and scalable, reliable (in data measurement, data communication, data analysis), user-friendliness, fast, fault-tolerant, low power of data communications [31], [32].

So that gain operational efficiencies, body wireless network implementations must ponder that significant issues depend on the proper coverage area in most of the human body. Small coverage area causes to body temperature and change location, and movement of nodes. So, the implementation of the network is vital aspect [33]. Moreover, exist major challenges between BANs and applications. For example, increased attenuation for communicating application, data rate, power consumption, trade-off between processing and communication, storage energy harvesting. In summary, we classified power efficient mechanism for BANs applications in scheduled contention, lower power listening, and TDMA based mechanisms.

Some challenging issues exist in the Wearable Health Monitoring System (WHMS) for example, battery technologies and energy scavenging, sensor miniaturization and efficiency design, security and validation of information, standardization and cooperation between different communication levels.

The most critical limitation is the energy source for gathering, processing, and transfer data for extending the lifetime of the network. Hence, to widespread the lifespan of the network, particular implanted nodes is necessary. Therefore, especially focused should be given to network lifetime when selecting or implementing communication protocols for WBANs such as routing and so on [34]. In this regard, routing algorithms are designed respect to energy challenge that can be classified into ten categories including: Thermal-Aware, Cluster and Tree-Based, Medium Access Control, Cross-Layer, Opportunistic, Restriction of Location and Number of Relays, Mobility-Aware, Link-Aware, QosAware, Hybrid protocol. The classification of the body area network application is shown in Fig. 2 [35].

The patient needs to be capable of moving easily. For instance, motions of the hands, walking, sleeping, running, twisting, up to and down stairs, etc. this category named "Mobility-aware" [36], [37]. Protocols that investigate the location and placement and relay of nodes are the category of "location restriction and number of relays" [38], [39]. This category uses multi-hop for data transferring, that cause reduces energy consume. Also, determine location case to increasing packet delivery rate and reduce packet drops.

Some protocols deal with the link status between the transmitter and the receiver for exchange information, including packet delivery ratio, HELLO message and signal strength. This category named "Link-aware" [40], [41]. Any protocol in this category that considers the link status for direct impact on various factors, include energy consumption, delay, reliability. Another category is links between the source and destination with cluster and tree for data transmission is "cluster and tree based" protocols [42]. This category is efficient in improving WBANs by using tree-based methods for allocating nodes and also gathering data, that cause reduce energy consumption. Next classification composed of multiple layers, containing network layer and transport layer, to improve WBANs. In other words, improve the efficiency and interaction between the protocols and two or more layers of the protocol stack.

This category named "Cross-layer" [43]. Also, another category related to the communication channel is "opportunistic" protocols [43]. This category discusses on how sensor nodes achievement of the communication channel. "Medium Access Control" is another category that focuses on energy consumption and cost. According to access the communication channel MAC protocols have been divided into two subcategories of scheduled and random protocols [44], [45]. 
The movements of the body may effect on topology networking capabilities, communications, or signal reception. However, the most significant restriction of energy is its source in which the body sensor network node is equipped with a small battery. The Sensors node in WBANs perform different activities, such as sensing, processing, analyzing which radiation absorption and heating effects on the human body; also because, if excessive heat will damage body tissues. So, mechanisms need to be supplied to impede the temperature rise in the nodes; for example, limited or traffic controls algorithms. This class named "thermal-aware" [46], [47]. For instance, the Thermal Aware Routing Algorithm (TARA) that routes data away from high temperature areas [47]. Packets are receding from the heated zone and rerouted via alternate paths. The disadvantage of TARA is from low network lifetime and low reliability into account and high ratio of dropped packets. The development and smarter of TARA is Least Total Route Temperature (LTRT) [48] that the node temperatures are modified on to graph weighs and minimum temperate routes are acquired. But LTRT suffers that a node needs to know the temperature of all nodes in the network.

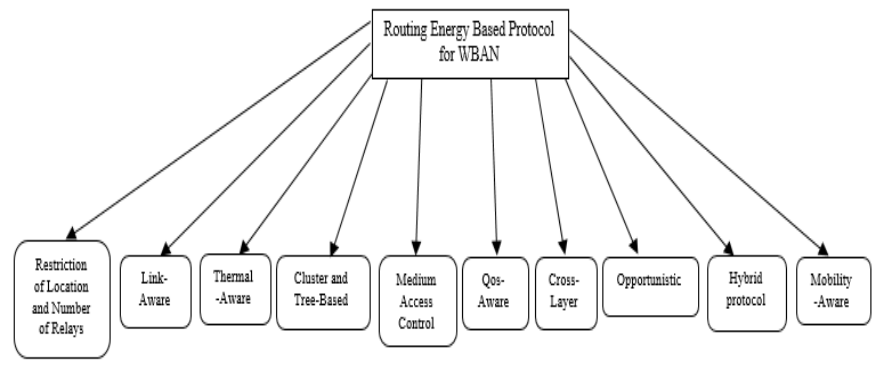

Fig. 2. Classification of routing protocols in body area networks with respect to energy

Energy efficiency requirements in MAC protocols have been evaluated in [49]. The method is proposed [50] to reduce power consumption by data aggregation mechanism. The energy-efficient and reliable protocol has been proposed in [51]. The protocol for patient monitoring has been presented in [52] that investigated location and position. Relay nodes placement schemes for minimizing energy consumption proposed in [53]. All of these protocols are the category of "Qos-Aware".

The last category is mixture of other categories called "Hybrid protocol". The protocol can be the mixture of two or more category for instance, link status and MAC. Fig. 2 shows classification of routing protocols in WBANs based on the consumed energy. Table 5 summarizes the examples of routing protocols with respect to energy in WBANs.
Cloud computing is a new method that able to sorting, processing, delivering, securing, analyzing, and distributing data streams [58] that relay on signal characteristics and the rate of data production and the sensing parameters. The algorithm processing can provide additional information for monitoring, emotion detection, activity recognition, skin prevention. Cloud computing in WBANs has some challenges such as, data management (collected and store data in a specific time and space and locations), data processing, data analysis (modeling and analysis tools for different applications), communication interface between the cloud and BAN resources, and stream data management for collecting and cleaning and aggregating and transferring and storing data. Also, aggregation and real-time processing of large scale data information.

Scalability is other challenges of WBANs communications [59]. Moreover, flexible system should be able to handling and configure it self-automatically. Therefore, selforganization and self-maintenance and self-management should be supported. Providing quality of service is another issue that related to the WBANs, where service is the appropriate service depends on their application and the nature of transport sensitive data [60]. For instance, when the WBANs implemented to monitor and support the patient's health care status, the information must be transfer real-time. Delays in the transfer of significant or critical alarms may be disastrous [61]-[63].

Another significant factor of WBANs applications is security of information. For instance, data confidentiality (transmit information private and encryption the information), data authenticity (verify the data is being sent from the trust center and not a false adversary), data integrity (verify when data is transmitted in an insecure) and data freshness (guarantees data in transmission). The security and the privacy of the collected personal medical data for protection should be encrypted to protect the patient privacy.

WBANs nodes should ensure integrity, high accuracy, confidentiality, and authenticity of data downloaded [64]-[66]. A privacy enhanced authentication scheme for the medical information system is proposed in [67], however, in [68] by Kumari et al. proposed scheme for verifying the attack, online password guessing attack and imitation attack. The digital signature is investigating in [69] to ensure the security of information that can ensure confidentiality of information. False alarms or Adding false data may lead to misleading results on patient safety. Result in a life threatening for the patient. Thus, security in WBANs should be established in various layers and levels for instance the physical layer and the network layer. Nonetheless, security upstairs may increase the energy consumption and influence the network lifetime [70], [71]. 
TABLE IV. APPLICATION AND USAGE OF WBANS

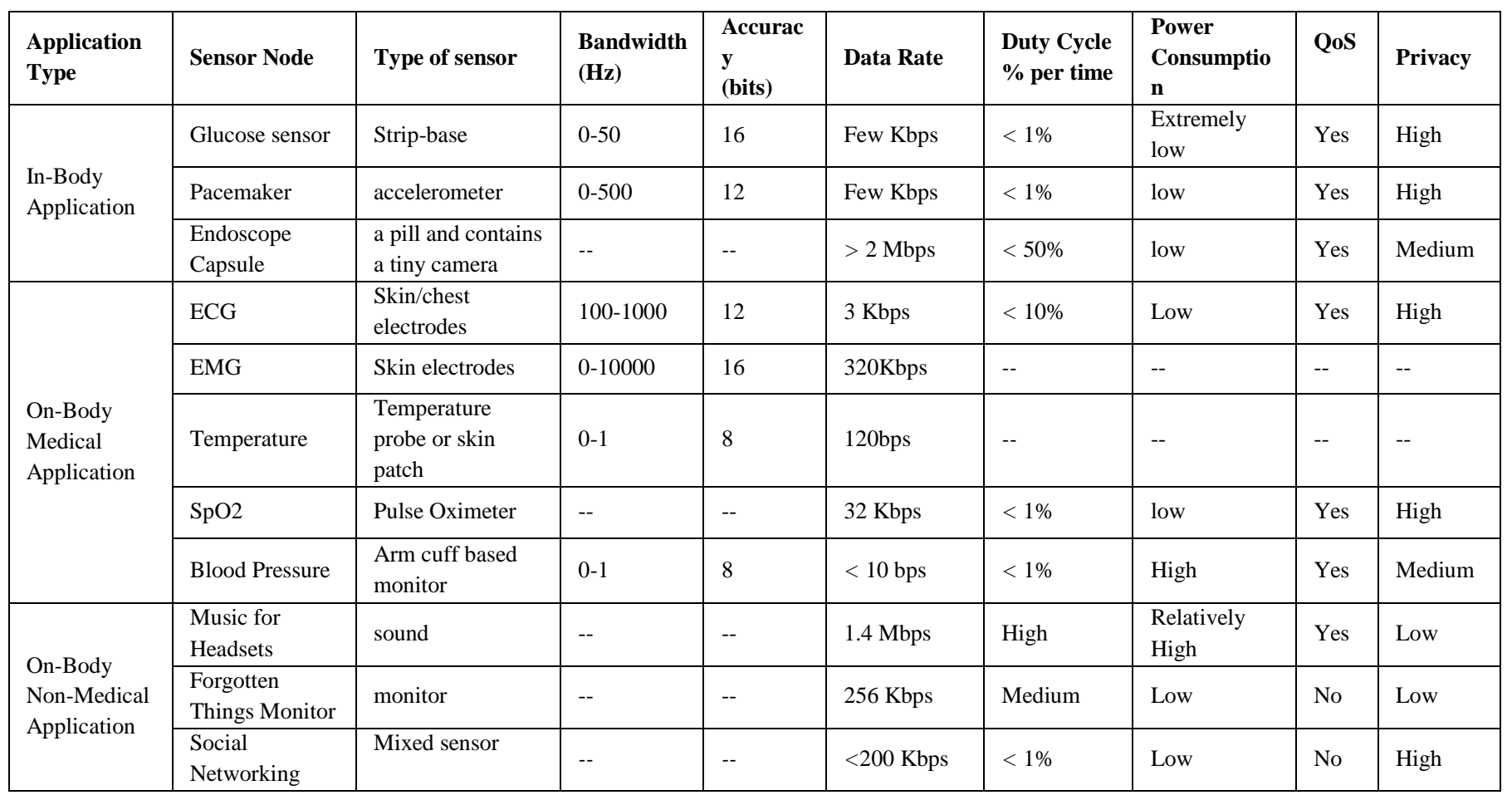



Fig. 3. Application for WBANs. 
TABLE V. Summarize THE EXAMPLES OF ROUTING PROTOCOLS WITH RESPECT TO ENERGY IN WBANS

\begin{tabular}{|c|c|c|c|c|c|c|c|c|}
\hline $\begin{array}{l}\text { Type of } \\
\text { protocols }\end{array}$ & Protocol & Author & $\begin{array}{l}\text { Date[] } \\
\text { Ref [] }\end{array}$ & Advantage & Disadvantage & +Simulator & $\begin{array}{l}\text { Energy } \\
\text { Consumptio } \\
\text { n }\end{array}$ & Goal \\
\hline \multicolumn{9}{|l|}{$\begin{array}{l}\text { Mobility- } \\
\text { Aware }\end{array}$} \\
\hline & $\begin{array}{l}\text { IM- } \\
\text { SIMPLE }\end{array}$ & $\begin{array}{l}\text { Javaid, N., et } \\
\text { al. }\end{array}$ & $\begin{array}{l}2014 \\
{[36]}\end{array}$ & $\begin{array}{l}\text { stability period: Good } \\
\text { network lifetime: Good } \\
\text { throughput: Good } \\
\text { energy consumption: Good } \\
\text { Throughput Good } \\
\text { Stability: Good } \\
\text { Life Time: Intermediate }\end{array}$ & $\begin{array}{l}\text { packet drop: } \\
\text { high }\end{array}$ & - & Good & $\begin{array}{l}\text { Reducing energy } \\
\text { consumption }\end{array}$ \\
\hline & EERS & $\begin{array}{l}\text { Liang, L., Ge, } \\
\text { et al. }\end{array}$ & $\begin{array}{l}2014 \\
{[37]}\end{array}$ & $\begin{array}{l}\text { network lifetime: Very } \\
\text { Good } \\
\text { energy consumption: Low } \\
\text { delay: Low }\end{array}$ & Overhead: high & Lab Room & Low & $\begin{array}{l}\text { Achieving } \\
\text { higher reliability } \\
\text { and energy } \\
\text { efficiency }\end{array}$ \\
\hline \multicolumn{9}{|c|}{$\begin{array}{l}\text { Restriction } \\
\text { and number of } \\
\text { relay } \\
\end{array}$} \\
\hline & REEC & $\begin{array}{l}\text { Sandhu MM, } \\
\text { et al. }\end{array}$ & $\begin{array}{l}{[38]} \\
2014\end{array}$ & $\begin{array}{l}\text { stability period: Good } \\
\text { network lifetime: Good } \\
\text { throughput: Good } \\
\text { Residual energy: Good }\end{array}$ & - & -- & Good & $\begin{array}{l}\text { Reliable energy- } \\
\text { efficient critical } \\
\text { data routing }\end{array}$ \\
\hline & EAWD & Elias J & $\begin{array}{l}{[54]} \\
2014 \\
\end{array}$ & $\begin{array}{l}\text { energy consumed: Low } \\
\text { does not need to install } \\
\text { additional relays }\end{array}$ & - & $\begin{array}{l}\text { 3D } \\
\text { electrom }\end{array}$ & Low & $\begin{array}{l}\text { increase the } \\
\text { network lifetime }\end{array}$ \\
\hline & $\begin{array}{l}\text { Braem, } \\
\text { et al. }\end{array}$ & $\begin{array}{l}\text { Braem B, et } \\
\text { al. }\end{array}$ & $\begin{array}{l}{[39]} \\
2007\end{array}$ & network lifetime: Good & $\begin{array}{l}\text { There is not the } \\
\text { possibility of } \\
\text { the continuous } \\
\text { use of relays, so } \\
\text { the cooperation } \\
\text { technique has } \\
\text { been proposed } \\
\text { instead. }\end{array}$ & -- & Good & $\begin{array}{l}\text { Energy } \\
\text { efficiency of } \\
\text { communication } \\
\text { despite path loss }\end{array}$ \\
\hline \multicolumn{9}{|l|}{ Link-Aware } \\
\hline & $\begin{array}{l}\text { IM- } \\
\text { Simple }\end{array}$ & $\begin{array}{l}\text { Javaid, N. , et } \\
\text { al. }\end{array}$ & $\begin{array}{l}{[36]} \\
2014\end{array}$ & $\begin{array}{l}\text { stability period: Good } \\
\text { network lifetime: Good } \\
\text { throughput: Good } \\
\text { energy consumption: Good }\end{array}$ & $\begin{array}{l}\text { packet drop: } \\
\text { high }\end{array}$ & --- & Good & $\begin{array}{l}\text { Reducing energy } \\
\text { consumption }\end{array}$ \\
\hline & AMR & $\begin{array}{l}\text { Ortiz AM, et } \\
\text { al. }\end{array}$ & $\begin{array}{l}{[55]} \\
2012\end{array}$ & $\begin{array}{l}\text { network lifetime: Good, } \\
\text { packet delivery rate: } \\
\text { increased data loss: } \\
\text { decreased } \\
\text { residual energy: high }\end{array}$ & $\begin{array}{l}\text { Requires } \\
\text { additional } \\
\text { packet } \\
\text { switching } \\
\text { between nodes }\end{array}$ & --- & & $\begin{array}{l}\text { Adaptive multi- } \\
\text { hop tree-based } \\
\text { routing; } \\
\text { improving } \\
\text { network } \\
\text { performance } \\
\end{array}$ \\
\hline & EERS & $\begin{array}{l}\text { Liang, L., Ge, } \\
\text { et al. }\end{array}$ & $\begin{array}{l}{[56]} \\
2014\end{array}$ & $\begin{array}{l}\text { network lifetime: high } \\
\text { energy consumption: low } \\
\text { delay: low }\end{array}$ & overhead : high & Lab room & & $\begin{array}{l}\text { Achieving } \\
\text { Higher } \\
\text { reliability and } \\
\text { energy } \\
\text { efficiency }\end{array}$ \\
\hline & $\begin{array}{l}\text { CO- } \\
\text { LAEEBA }\end{array}$ & $\begin{array}{l}\text { Ahmed, S., et } \\
\text { al. }\end{array}$ & $\begin{array}{l}{[41]} \\
2015\end{array}$ & $\begin{array}{l}\text { stability period: Very Good } \\
\text { network lifetime: Very } \\
\text { Good } \\
\text { throughput: Very Good } \\
\text { residual energy: Good } \\
\text { path loss: Good }\end{array}$ & -- & --- & & $\begin{array}{l}\text { Providing a link- } \\
\text { aware and } \\
\text { energy-efficient } \\
\text { protocol }\end{array}$ \\
\hline \multicolumn{9}{|l|}{$\begin{array}{l}\text { Thermal- } \\
\text { Aware }\end{array}$} \\
\hline & IA-MAC & $\begin{array}{l}\text { Ahmad A, et } \\
\text { al. }\end{array}$ & $\begin{array}{l}2014 \\
{[46]}\end{array}$ & $\begin{array}{l}\text { energy consumption: Low } \\
\text { Cost: Low } \\
\text { network lifetime: Good } \\
\text { packet loss rate: low } \\
\text { Packet delivery ratio: } \\
\text { Intermediate } \\
\text { Number of packet drops: } \\
\text { Good }\end{array}$ & $\begin{array}{l}\text { packet } \\
\text { transmission: } \\
\text { low } \\
\text { cycle count: low }\end{array}$ & -- & Good & $\begin{array}{l}\text { Improving } \\
\text { medium } \\
\text { access control; } \\
\text { achieving } \\
\text { adaptive } \\
\text { sleep/wakeup } \\
\text { mechanism }\end{array}$ \\
\hline & LTRT & $\begin{array}{l}\text { Takahashi D, } \\
\text { et al. }\end{array}$ & $\begin{array}{l}{[48]} \\
2007\end{array}$ & $\begin{array}{l}\text { temperature rise: Low } \\
\text { Delay: Low }\end{array}$ & $\begin{array}{l}\text { Packet delivery } \\
\text { rate: High }\end{array}$ & Java & Low & $\begin{array}{l}\text { Reducing the } \\
\text { temperature rise }\end{array}$ \\
\hline
\end{tabular}




\begin{tabular}{|c|c|c|c|c|c|c|c|c|}
\hline & & & & average hop count: low & & & & $\begin{array}{l}\text { of the implanted } \\
\text { sensor } \\
\text { nodes in the } \\
\text { human body }\end{array}$ \\
\hline & TSHR & $\begin{array}{l}\text { Ahourai F, et } \\
\text { al. }\end{array}$ & $\begin{array}{l}{[57]} \\
2009\end{array}$ & $\begin{array}{l}\text { temperature rise: Low } \\
\text { Delay: Intermediate } \\
\text { packet drop: zero } \\
\text { network lifetime: long }\end{array}$ & $\begin{array}{l}\text { packet delivery: } \\
\text { high }\end{array}$ & $\mathrm{C}++$ & Low & $\begin{array}{l}\text { Efficient } \\
\text { thermal-aware } \\
\text { routing }\end{array}$ \\
\hline & TARA & $\begin{array}{l}\text { Tang Q, } \\
\text { Tummala N, } \\
\text { et al. }\end{array}$ & $\begin{array}{l}{[47]} \\
2005\end{array}$ & $\begin{array}{l}\text { Temperature rise: High } \\
\text { Temperature: balance }\end{array}$ & $\begin{array}{l}\text { packet delay: } \\
\text { high } \\
\text { network } \\
\text { lifetime: short }\end{array}$ & Matlab & Low & $\begin{array}{l}\text { Avoiding } \\
\text { hotspots during } \\
\text { packet } \\
\text { transmission } \\
\end{array}$ \\
\hline \multicolumn{9}{|l|}{ Cross-Layer } \\
\hline & COMR & $\begin{array}{l}\text { Abbasi UF, et } \\
\text { al. }\end{array}$ & $\begin{array}{l}{[43]} \\
2014\end{array}$ & $\begin{array}{l}\text { network lifetime: Good } \\
\text { delay: Good } \\
\text { energy consumption: Good }\end{array}$ & $\begin{array}{l}\text { packet delivery } \\
\text { ratio: decrease }\end{array}$ & Omnet++ & Good & $\begin{array}{l}\text { Improving } \\
\text { reliability by a } \\
\text { cross-layer } \\
\text { opportunistic } \\
\text { method }\end{array}$ \\
\hline \multicolumn{9}{|l|}{$\begin{array}{l}\text { Cluster and } \\
\text { Tree-Based }\end{array}$} \\
\hline & RTT & $\begin{array}{l}\text { Chebbo H, et } \\
\text { al. }\end{array}$ & $\begin{array}{l}{[42]} \\
2012\end{array}$ & Reliability: high & $\begin{array}{l}\text { a large number } \\
\text { of relays }\end{array}$ & $\begin{array}{l}\text { Channel } \\
\text { sounder }\end{array}$ & Good & $\begin{array}{l}\text { Reliable data } \\
\text { transfer }\end{array}$ \\
\hline \multicolumn{9}{|l|}{$\begin{array}{l}\text { Medium } \\
\text { Access } \\
\text { Control }\end{array}$} \\
\hline & $\begin{array}{l}\text { BODY } \\
\text { MAC }\end{array}$ & Fang G, et al. & $\begin{array}{l}{[44]} \\
2009\end{array}$ & $\begin{array}{l}\text { bandwidth allocation: } \\
\text { Good } \\
\text { delay: decreases } \\
\text { power consumption: Good }\end{array}$ & -- & $\begin{array}{l}\text { OPEN-ZB } \\
\text { TOOLSET }\end{array}$ & Good & $\begin{array}{l}\text { Presenting a } \\
\text { MAC protocol } \\
\text { for energy } \\
\text { efficiency }\end{array}$ \\
\hline & $\begin{array}{l}\text { MED } \\
\text { MAC }\end{array}$ & $\begin{array}{l}\text { Timmons NF, } \\
\text { et al. }\end{array}$ & $\begin{array}{l}{[45]} \\
2009\end{array}$ & $\begin{array}{l}\text { power efficiency: Good } \\
\text { overhead: no } \\
\text { synchronization }\end{array}$ & --- & OPNET & Good & $\begin{array}{l}\text { Presenting a } \\
\text { medical MAC } \\
\text { protocol for } \\
\text { energy-efficient } \\
\text { and adaptable } \\
\text { channel access }\end{array}$ \\
\hline \multicolumn{9}{|l|}{ Opportunistic } \\
\hline & COMR & $\begin{array}{l}\text { Abbasi UF, et } \\
\text { al. }\end{array}$ & $\begin{array}{l}{[43]} \\
2014\end{array}$ & $\begin{array}{l}\text { network lifetime: Good } \\
\text { delay: Good } \\
\text { energy consumption: Good }\end{array}$ & $\begin{array}{l}\text { packet delivery } \\
\text { ratio: decrease }\end{array}$ & Omnet++ & Good & $\begin{array}{l}\text { Improving } \\
\text { reliability by a } \\
\text { cross-layer } \\
\text { opportunistic } \\
\text { method }\end{array}$ \\
\hline
\end{tabular}

\section{RADIO TECHNOLOGIES OF WBANS}

The general standard used in Body Wireless Communication is IEEE 802.15.1 (Bluetooth) and 802.15.4 (Zigbee), a primitively section of the 802.15 operate in a wireless personal area network (WPAN). Bluetooth is a shortrange communication system that replaces the cables for electronic devices. Two categories of basic rate (BR) configuration consist of Enhanced Data Rate (EDR), and Low Energy (LE). Then, proposed Zigbee for a special case of sensor networks that extensively adopted to perform WBANs.

IEEE Standard Association recommendation the IEEE 802.15 task groups 6 for low power devices and operated on, in or around the human body for different applications in WBANs. Generally, the characteristics of the physical layer are classified in RF communication (Radio Frequency), movement of the body, None-RF communication [72]. This layer is responsible for archiving some tasks such as, active and reactive of the radio transceiver. The choice of this layer depends on usage and aspect of the application, on medical or non-medical, implantable sensor, wearable sensor, surrounding sensors. Monitoring critical signs, for example heart rate, body position, blood pressure, and oxygen saturation are now performed through small sensors [73].
These lightweight and intelligent devices are able to measure physical events, processing and wireless transmission. Wireless sensor particles are placed intra-body or implanted on the body and extend or extra-body of the smallest in a short distance of wireless networks surround the human body is done by using an RF transmission technology [74].

In late 2011, the standard of wireless network protocols was approved. The standard has explained three physical layers, Ultra Wideband (UWB), Narrow band (NB), HumanBody Communication (HBC) [75]. All of them extract to the conclusion that propagate physical layer operations based on radio frequency, whereas human body communication based on non-radio frequency. Numerous researchers have been scrutinizing inside the human body by narrowband radio signals and ultra wide band in the path lose [72].

Multiple frequency bands use monitoring operation of the physical narrowband with $402-405 \mathrm{MHz}$ frequency in implantable devices. Three various bands of frequency (863$956 \mathrm{MHz}$ ) are for coverage wearable applications, and from 2360 to $2400 \mathrm{MHz}$ they are for medical applications. Moreover, UWB PHY operates at higher frequency regions, particularly the low $(3-5 \mathrm{GHz})$ and high $(6-10 \mathrm{GHz})$ bands with a channel bandwidth of $499.2 \mathrm{MHz}$ [76]. HBC is 
classified in two-body communications channel (BCC) or internal body communications (IBC) [77]. IBC can reuse frequency in the following desirable features, security, and energy [78]. Since NB is lower frequencies, so numerous numbers of healthcare applications are matched.

Table 6 summarizes the characteristics of the body communication channel and internal body communications [72], [79]. HBC has some advantages such as, intrinsic security, saving, energy consumption compared to UWB. Molecular communication use molecules as messages transferred between a sender and a receiver by using nanotechnology for Nano medicine application and alternative of ultrasonic communications [80].

Generally, IBC communication within the body can be categories into two sets based on how the electrical signals are transmitted, Capacitive coupling (electrical field) and the galvanic pair (waveguide) [74]. In both kinds of the sender and receiver, two pairs of electrodes are needed. In the coupling capacitor, only one of the electrodes of the deliver and the receiver is connected to the body, while the other electrode (ground electrode) is floating. In the galvanic pair method, both the sender and the receiver electrode are connected to the human body [78].

Capacitive theory with communication within the body by coupling capacitor engender is attached from human body to the around environment. The signal is created between transmitter and receiver channel by creating a loop through the surrounding. The transmitter signal electrode genders the electric field in the human body. The electrical signal is controlled by an electrical potential and acts as a conductor with the earth and return path in the body [79]. On the other hand, a galvanic couple of pairs of alternating current is achieved in the human body, which is controlled by the AC current in the body as a deliberation line [77]. Using various electrical signals between the electrodes of the transmitter in the galvanic coupling with communications inside the body, main release of the two signal transmitter electrode and a weak signal in the receiver occurs by two electrodes [74]. Generally, ion content in the human body carries information by galvanic coupling method. Table 7 summarizes the capacitive coupling method and compares galvanic coupling [72].

TABLE VI. COMPARISON BETWEEN IBC AND RF

\begin{tabular}{|l|l|l|}
\hline & IBC & RF (NB, UWB) \\
\hline $\begin{array}{l}\text { Communication } \\
\text { Medium }\end{array}$ & Human Body & Air \\
\hline Frequency Band & $\begin{array}{l}\text { Centered at } 21 \mathrm{MHz} \\
\left(f_{B W}=5.25 \mathrm{MHz}\right)\end{array}$ & $\begin{array}{l}\text { Different bands } \\
(402 \mathrm{M}-10 \mathrm{GHz})\end{array}$ \\
\hline Data Rate & less than $2 \mathrm{Mb} / \mathrm{s}$ & less than $13 \mathrm{Mb} / \mathrm{s}$ \\
\hline Transmission Range & less than $2 \mathrm{~m}$ & $10 \mathrm{~m}$ \\
\hline Signal Attenuation & Low & $\begin{array}{l}\text { High(Body } \\
\text { Shadowing })\end{array}$ \\
\hline On-Body Antenna & No & Yes \\
\hline Energy Efficiency & High & Low \\
\hline
\end{tabular}

TABLE VII. COMPARE BETWEEN TWO METHODS OF COMMUNICATION IN WBANS

\begin{tabular}{|l|l|}
\hline Galvanic Coupling & Capacitive Coupling \\
\hline $\begin{array}{l}\text { Quality of signal influeneed by } \\
\text { dielectrics of human tissue. }\end{array}$ & $\begin{array}{l}\text { Quality of signal influeneed by the } \\
\text { environment around the body. }\end{array}$ \\
\hline Lower transmission data rate. & Higher transmission data rate. \\
\hline Must be connect with body tissue. & $\begin{array}{l}\text { Dose not require connect with the } \\
\text { human body tissue. }\end{array}$ \\
\hline $\begin{array}{l}\text { Location base, exact distance and } \\
\text { orientation along the body. }\end{array}$ & $\begin{array}{l}\text { Interference the surrrounding } \\
\text { devices }\end{array}$ \\
\hline Modeled by a waveguide. & Modeled by a perfect conductor. \\
\hline Ground is not require as a refrence. & Ground is require as a refrence. \\
\hline Domain of signal is the body tissue. & $\begin{array}{l}\text { Domain of signal is the } \\
\text { environment. }\end{array}$ \\
\hline
\end{tabular}

\section{PATIENT Monitoring AND TELEMEDicine SySTEMS}

Monitoring human activity with WBANs classification is: Remote monitoring (elderly, baby, staff, etc.), security (soldiers), training (sport), emergency situation (rescue, firefighters), safety (elderly, personal safety, etc.) [25].

The recent innovation in telecommunications and information technology provide clinical health care system at a distance. This system improves health care quality and helps the barriers of distance, special in rural communities that they are inaccessible. Developments in the mobile application, to health care system professionals in various locations, permit the patient to share information and discuss issues of helping them to be used in the same place. A telemedicine system through mobile technology can significantly reduce the overall cost and it can save time [81]. The incidence of disease such as kidney problems, Alzheimer's disease, Parkinson disease, anxiety disorder, and infant death syndrome, assistance to the disable people can be reduced by providing health care [82].

Disable people, for example paraplegic diseases used for monitoring the position of the legs and nerves and simulate the positioned of the muscles. BANs for disability people classified in way finding for blind persons, monitoring elderly people, activity monitoring, posture detection, rehabilitation. This kind of device can direct involvement for disabling the person, such as electric wheelchair or control the function invention, for instance fall detection system. In [83] suggested the architecture for fall and accident detection that consist of a gyroscope and accelerometer and a magnetometer that placed on the hip and the user's leg and on the upper torso. The result depicts that this system can investigate and reduce the fall detection and accident in $85 / 6 \%$.

In chronic diseases that usually take more than three months. The diseases kill 17 million people a year, which can be reduced or prevented by a strategy of suitable health care system. Common chronic diseases exist, for example, asthma cancer, diabetes, and viral diseases such as hepatitis $\mathrm{C}$. In the following, some of the disease can support and monitor, the vital sign of patients are explained. 
Diabetes includes a metabolic disease in which blood glucose in the long term is more than one level. Diabetes is resulting not enough insulin production in the pancreas. In the early stages of diabetes, people may have no symptoms. Many people are identified random in a test or during screening. Increasing blood sugar, diabetes symptoms become apparent. Frequent urination, Polydipsia, overeating, weight loss, despite increased appetite; fatigue and blurred vision are common early symptoms of diabetes. Many patients diagnosed with diabetes or have diabetes for several years. Worldwide, more than 246 million people endure from diabetes [13]. A number that is expected to reach 438 million in 2030 to about 7.8 percent of the population accounts for young people. Conclusion monitoring and proper dosage reduce the risk of fainting. By using WBANs to automatic, monitoring diabetes, as soon as high or low level of glucose, a signal can be transferred to the system and alter the patient for doing proper actions.

Cardio Vascular Disease (CVD) is the leading death in the world and includes almost $30 \%$ of all deaths globally. Based on the World Health Organization, 17.5 million people worldwide each year die from heart attack or stroke [12]. Most of these deaths could be avoided with suitable medical health care. This is an instance to show the need for constant monitoring of wireless networks and their usefulness in the body.

Numerous of people suffer diabetes or cardiovascular diseases, and percent of population aged 60 years and elderly population will grow in the future that is predicted to prompt to 1200 million people in year 2025. These disease rapid epidemics show many potential customers and the absence of the medical center and staff and nursing homes for older people are observed. WBANs continuously monitor the vital physiological parameters of the body [84]. Therefore, there is no need the patient stays in hospital for a long time and do not spend lots of money for health care. For instance, the place of a wireless sensor network used to monitor a patient's medical body is explained in Fig. 4 [16].

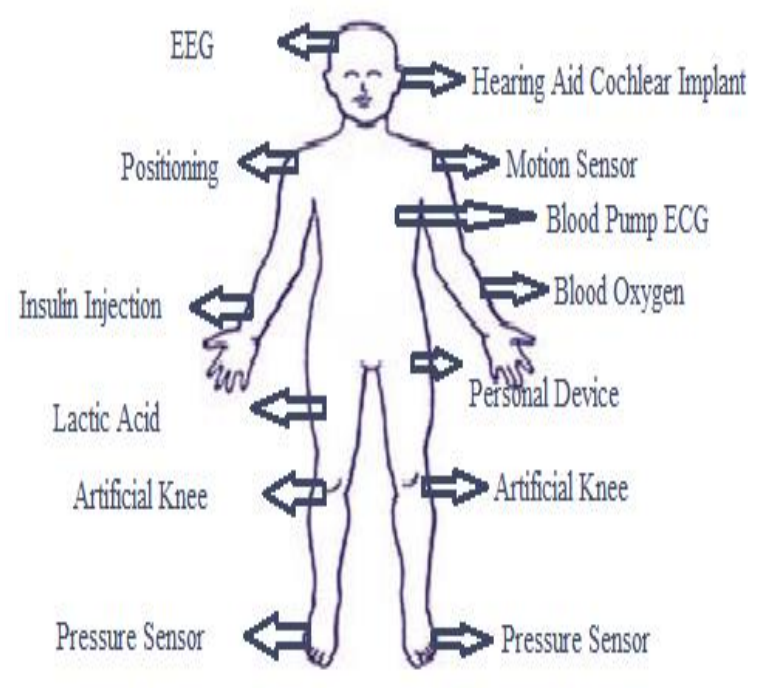

Fig. 4. Example of patients monitoring in WBANs
Different sensors installed on clothes that connect with the body or even under the human skin of a person to measure temperature, control the blood pressure, heart rate, ECG, EEG, respiration rate, SPO2 and after measuring the device; the patient can get medications from the system [16]. Accelerometer sensors are used to monitor and distinguish body posture that placed on some strategically location on the human body. The WBANs has a critical role in real-time monitoring of healthcare. Any wearable sensors monitor a special physiological sign. These drugs can be predetermined and is delivered by an external source or instant after the sensor notice a problem [85].

Cancer is one of the biggest ventures to human life. A series of partial sensors that are able to monitor cancer cells in the human body sensor integrated network and this allows doctors to detect tumors without biopsy. It is estimated that by the National Center for Health Statistics, 2020 with an increase of 50 percent, cancer deaths reach to 15 million.

The epileptic is seizures due to abnormal activity of nerve cells in the brain cortex. Brain imaging and blood tests may diagnose the disease. Epilepsy often confirmed by electroencephalogram (EEG) and imaging. Electroencephalogram (EEG) can help show brain activity increased risk of seizures. In the diagnosis of epilepsy, EEG may help distinguish the kind of seizure or already syndrome. Diagnostic imaging by CT scan and MRI after a febrile convulsion to detect structural problems in and around the brain is recommended [86].

WBANs can also be used to prepare assistance to people who are not acting well. To illustrate, paraplegic patients can be equipped with sensors to determine the position of the legs, or the sensor is connected to the nerve and creates to restore the ability to move. An additional example is the help for the vision. The artificial retina includes a matrix of miniature sensors, which can be implanted in the human eye. Artificial retina chips deliver electrical pulses to the brain and nervous system. The input can be gained locally by light sensor or by an external camera in a pair of sensitive glasses. Therefore, help patients that limited or no eye to see [87].

Body sensor networks for monitoring patients with asthma and allergy factors in the air and provide feedback in real-time to help a doctor [13]. Location-based system was designed, which diagnosed oversees environmental factors and allergy diagnosis in patients [88]. Approximately 300 million people in worldwide suffer from asthma and 250000 people death every year death.

There are other survey studies in the literature [30], [89], [90]. This overview currently explains thousands of opportunities where wireless sensor networks are suitable for body. The significant characteristic of all these programs is that the wireless sensor network is used to improve the quality of the user's life.

\section{CONCLUSION}

The accelerating health care cost and high demand for medical services call for innovative solutions to ensure fast and cost-effective medical monitoring cause for evolution in health care systems. Becoming mature, enough in wireless 
communication radio technologies led to emerge WBANs. This network consists of miniature electronics and low-power sensors that attached or implanted on body for transferring information of monitoring patient health in all-day and anywhere. With the current technological evolution, these networks have various usages in different scope not only in medicine, but also in entertainment, fight, travel, industry, game, sport and so on. Thus, recently researchers focused on issues related to improve communication and applications.

We believe that, using WBANs can cause patient no longer stays in the hospital and attains easier communication with doctors and gain online medical consultation and save time and cost for care. These technologies can regard the next step in improving personal health care systems. In soon, wearable BANs could be used for virtual social interactions: all data can be swapped through BANs when meeting each other or share in social networks. This information can gather processing and management by ad-hoc mobile sensors and different applications in events and analysis information for preventing disasters and prevention medical emergency.

In this survey, we have reviewed the current research on WBANs. In order to find and investigate the most relevant research articles in this area. First, we present some fundamental mechanism and concept in WBANs and review challenges and numerous WBANs applications. Then, we highlighted to need to be addressed to make WBANs for a wide range of applications for researchers and developers.

\section{REFERENCES}

[1] S. L. P. Tang, "Recent developments in flexible wearable electronics for monitoring applications," Trans. Ins.Meas. Control, 2007, vol. 29, pp. 283-300.

[2] Deena M. Barakah and Muhammad Ammad-uddin, "A Survey of Challenges and Applications of Wireless Body Area Network (WBAN) and Role of a Virtual Doctor Server in Existing Architecture," Third International Conference on Intelligent Systems Modelling and Simulation, 2012.

[3] R. Paradiso and G. Loriga and N. Taccini, "A wearable health care system based on knitted integral sensors," IEEE Trans. Inf. Technol. Biomed., 2005, vol. 9, no. 3, pp. 337-344.

[4] Sana Ullah, et al., "A Comprehensive Survey of Wireless Body Area Networks On PHY, MAC, and Network Layers Solution," Springer Science and Business Media, 2010.

[5] Hande Alemdar and Cem Ersoy NETLAB, "Wireless sensor networks for healthcare: A survey,” 2010, Computer Networks 54 2688-2710.

[6] Custodio, V., et al., "review on architectures and communications technologies for wearable health-monitoring systems Sensors," 2012, 12 (10), 13907-13946.

[7] Lai, X., et al., "A survey of body sensor networks Sensors," 13(5), (2013), 5406-5447.

[8] Liu, X., Zheng, et al., "Power and area efficient wavelet-based on-chip ECG processor for WBAN, "In International conference on body sensor networks, 2010, pp. 124-130.

[9] Atallah, L., et al., "Sensor placement for activity detection using wearable accelerometers," In International conference on body sensor networks, 2010, pp. 24-29.

[10] Liu, C., et al., "Clubfoot pattern recognition towards personalized insole design, In International conference on body sensor networks," 2010, pp. 273-276.

[11] Mitchell, E., et al., "Breathing feedback system with wearable textile sensors," In International conference on body sensor networks, 2010, pp. $56-61$.
[12] Samaneh Movassaghi and Justin Lipman, "Wireless Body Area Networks: A Survey," IEEE. Communications surveys \& tutorials, 2013.

[13] Ullah, S., et al. "A comprehensive survey of wireless body area networks," Journal of Medical Systems, 2012, 36, 1065-1094.

[14] Tang, Q., et al., "Communication scheduling to minimize thermal effects of implanted biosensor networks in homogeneous tissue," IEEE Transactions on Biomedical Engineering, 52(7), 1285-1294.

[15] Alexandros Pantelopoulos and Nikolaos G. Bourbakis, "A Survey on Wearable Sensor-Based Systems for Health Monitoring and Prognosis," IEEE transactions on systems, man and cybernetics, 2010, vol. 40, no. 1.

[16] Benoit Latre, et al., "A survey on wireless body area networks," Springer Science Business Media, LLC, 2010.

[17] P.TOBÓN, et al., "Context awareness in WBANs: a survey on medical and non-medical applications, Diana wireless communications for ehealth applications," IEEE Wireless Communications, 2013, 15361284/13/\$25.00.

[18] B. Sowell, M. Branine, J. Bowman, M. Hubbert, H. Sherwood, W. Quimby, "Feeding and watering behavior of healthy and morbid steers in a commercial feedlot," J. Anim. Sci. 77 (5) (1999) 1105-1112.

[19] M. Chu, S. Iguchi, D. Takahashi, T. Arakawa, H. Kudo, K.Mitsubayashi, "Wearable biosensor for monitoring tear glucose on rabbit eye as novel device of body sensor network," in: 5th International Conference on Intelligent Sensors, Sensor Networks and Information Processing (ISSNIP), 2009.

[20] S. Bouwstra, L. Feijs, W. Chen, S.B. Oetomo, "Smart jacket design for neonatal monitoring with wearable sensors," in: Sixth International Workshop on Wearable and Implantable Body Sensor Networks, BSN 2009.

[21] A. Basak, S. Narasimhan, and S. Bhunia, "KiMS: Kids' Health Monitoring System at day-care centers using wearable sensors and vocabulary- based acoustic signal processing," in: 13th IEEE International Conference on e-Health Networking Applications and Services (Healthcom), 2011.

[22] Fortino, G., et al., "Enabling effective programming and flexible management of efficient body sensor network applications," IEEE Transactions on Human-Machine Systems, 2013, 43(1), 115-133.

[23] Patel, M., and Wang, J. "Applications, challenges, and prospective in emerging body area networking technologies," IEEE Wireless Communications, 2010, 17(1), 80-88.

[24] Ragesh, G., and Baskaran, K., "An overview of applications, standards, and challenges in futuristic wireless body area networks," International Journal of Computer Science, 2012, 9(1), 180-186.

[25] Adnan Nadeem, Muhammad Azhar Hussain, Obaidullah Owais, Abdul Salam, Sarwat Iqbal, Kamran Ahsan, "Application specific study, analysis and classification of body area wireless sensor network applications," Computer Networks, Elsevier, 1389-1286, 2015.

[26] Zasowski, T., et al., "UWB for noninvasive wireless body area networks: channel measurements and results," in: IEEE conference on ultra wideband systems and technologies, 2003, pp. 285-289.

[27] Penzel, T., et al. "Acquisition of biomedical signals databases, IEEE Engineering in Medicine and Biology Magazine," 2001, 20(3), 25-32.

[28] Arnon, S., et al., "A comparative study of wireless communication network configurations for medical applications," IEEE Wireless Communications, 2003, 10(1), 56-61.

[29] Varshney, U., and Sneha, S., "Patient monitoring using ad hoc wireless networks: reliability and power management," IEEE Communications Magazine, 2006, 44(4), 49-55.

[30] Thaier Hayajneh and Ghada AlmashaqbehSana Ullah and Athanasios V. Vasilakos, "A survey of wireless technologies coexistence in WBAN: analysis and open research issues," Springer Science Business Media New York, 2014.

[31] G.H. Zhang, et al., "A biometric method to secure telemedicine systems," in: 31st Annual International Conference of the IEEE Engineering in Medicine and Biology Society, 2009, vol. 1, pp. 701704. 
[32] Schwiebert, L. and Gupta, S. K., and Weinmann, J., "Research challenges in wireless networks of biomedical sensors," In Proceedings of ACM MobiCom, 2001, pp. 151-165.

[33] Khan, J. Y., et al, "Wireless body area network (WBAN) design techniques and performance evaluation," Journal of Medical Systems, 2012, 36(3), 1441-1457.

[34] Ullah, S., et al, “A study of MAC protocols for WBANs Sensors," 2009, $10(1), 128-145$.

[35] M. Effatparvar1, M. Dehghan, A. M. Rahmani, "A comprehensive survey of energy-aware routing protocols in wireless body area sensor networks," Springer Science Business Media New York, 2016.

[36] Javaid, N., Ahmad, A., Nadeem, Q., Imran, M., and Haider, N., "iMSIMPLE: iMproved stable increased-throughput multi-hop link efficient routing protocol for Wireless Body Area Networks," Computers in Human Behavior. 51:1003 -1011, 2014. Doi: 10.1016/j.chb, 2014, 10.005.

[37] Liang, L., Ge, Y., Feng, G., Ni, W., and Wai, A.A.P., "A low overhead tree-based energy-efficient routing scheme for multi-hop wireless body area networks," Computer Networks. 70:45-58, 2014. Doi: 10.1016/j.comnet.2014.05.004.

[38] Sandhu MM, Akbar M, Behzad M, Javaid N, Khan ZA, Qasim U., "REEC: Reliable Energy Efficient Critical Data Routing in Wireless Body Area Networks," In Broadband and Wireless Computing, Communication and Applications (BWCCA), IEEE, Ninth International Conference on 2014 Nov 8, pp. 446-451.

[39] Braem B, Latre B, Moerman I, Blondia C, Reusens E, Joseph W, Martens L, Demeester P., "The need for cooperation and relaying in short-range high path loss sensor networks," In Sensor Technologies and Applications, IEEE, Sensor Comm, International Conference on 2007 Oct 14, pp. 566-571.

[40] Elias J, "Optimal design of energy-efficient and cost-effective wireless body area networks. Ad Hoc Networks," 2014, 13: 560-574. Doi: 10.1016/j. adhoc. 2013.10.010

[41] Ahmed, S., Javaid, N., Yousaf, S., Ahmad, A., Sandhu, M.M., Imran, M., Khan, Z.A., and Alrajeh, N., "Co-LAEEBA: Cooperative link aware and energy efficient protocol for wireless body area networks," Computers in Human Behavior. 51:1205- 1215, 2015. Doi:10.1016/j.chb.2014.12.051.

[42] Chebbo H, Abedi S, Lamahewa TA, Smith DB, Miniutti D, Hanlen L., "reliable body area networks using relays: restricted tree topology," IEEE, Computing, Networking and Communications (ICNC), 2012 International Conference, pp. 82-88, Maui, HI.

[43] Abbasi UF, Awang A, Hamid NH., "A cross-layer opportunistic MAC/routing protocol to improve reliability in WBAN," In Communications (APCC), IEEE, Asia-Pacific Conference on 2014 Oct 1 , pp. 36-41.

[44] Fang G, Dutkiewicz E., "BodyMAC: Energy efficient TDMA-based MAC protocol for wireless body area networks. In Communications and Information Technology," ISCIT 2009, IEEE 9th International Symposium on 2009 Sep 28, pp. 1455- 1459.

[45] Timmons NF, Scanlon WG., "an adaptive energy efficient MAC protocol for the medical body area network," In Wireless Communication, Vehicular Technology, Information Theory and Aerospace \& Electronics Systems Technology, 2009, , IEEE, Wireless VITAE, 1st International Conference on 2009 May 17, pp. 587-593.

[46] Ahmad A, Javaid N, Khan ZA, Imran M, Alnuem M., "iAMAC: Improved adaptive medium access control protocol for wireless body area networks," In Communications and Information Technologies (ISCIT), 14th International Symposium on 2014 Sep 24, pp. 156-160, Incheon, IEEE.

[47] Tang Q, Tummala N, Gupta S K, Schwiebert L, "TARA: thermal-aware routing algorithm for implanted sensor networks," In Distributed Computing in Sensor Systems, 2005, 3560:pp. 206-217 doi: 10.1007/11502593_17.

[48] Takahashi D, Xiao Y, Hu F., "LTRT: Least total-route temperature routing for embedded biomedical sensor networks," In Global Telecommunications Conference, GLOBECOM'07, IEEE, 2007 Nov 26, pp. 641-645.
[49] Kutty S, Laxminarayan JA., "towards energy efficient protocols for wireless body area networks," In Industrial and Information Systems (ICIIS), 2010 International Conference on 2010 Jul 29, pp. 31-34, Mangalore, IEEE.

[50] Liang, T., and Smith, D.B., "Energy-efficient, reliable wireless body area networks: cooperative diversity switched combining with transmit power control. Electronics Letters," 50(22):1641-1643, 2014. doi:10.1049/el.2014.2648.

[51] Sandhu MM, Javaid N, Akbar M, Najeeb F, Qasim U, Khan ZA., "FEEL: Forwarding Data Energy Efficiently with Load Balancing in Wireless Body Area Networks," In Advanced Information Networking and Applications (AINA), I.E. $28^{\text {th }}$ International Conference on 2014 May 13, pp. 783-789.

[52] Tauqir A, Javaid N, Akram S, Rao A, Mohammad SN., "Distance aware relaying energy-efficient: DARE to monitor patients in multi-hop body area sensor networks," In Broadband and Wireless Computing, Communication and Applications (BWCCA), IEEE, Eighth International Conference on 2013 Oct 28, pp. 206-213.

[53] Mohammad Ghamari, Balazs Janko, R. Simon Sherratt, William Harwin, Robert Piechockic and Cinna Soltanpur, "A Survey on Wireless Body Area Networks for eHealthcare Systems in Residential Environments," Sensor journal, MDPI, June 2016.

[54] Elias J, "optimal design of energy-efficient and cost-effective wireless body area networks," Ad Hoc Networks13: 560-574, 2014 doi:10.1016/j.adhoc.2013.10.010.

[55] Ortiz AM, Ababneh N, Timmons N, Morrison J., "Adaptive routing for multi hop IEEE 802.15. 6 wireless body area networks. In Software," Telecommunications and Computer Networks (SoftCOM), 2012 20th International Conference on 2012 Sep 11, pp. 1-5.

[56] Liang, L., Ge, Y., Feng, G., Ni, W., and Wai, A.A.P., "A low overhead tree-based energy-efficient routing scheme for multi-hop wireless body area networks," Computer Networks. 70:45-58, 2014. Doi: 10.1016/j.comnet.2014.05.004.

[57] Ahourai F, Tabandeh M, Jahed M, Moradi S., " A thermal aware shortest hop routing algorithm for in vivo biomedical sensor networks," In2009 Sixth International Conference on Information Technology: New Generations 2009 Apr 27, pp. 1612-1613.

[58] Ullah, S., Higgins, H., Braem, B., Latre, B., Blondia, C., Moerman, I., Saleem, S., Rahman, Z., Kwak, K.S., "A comprehensive survey of wireless body area networks," Journal of medical systems. 36(3):10651094, 2012.

[59] Cheng, S. et al, "Racoon: A multiuser QoS design for mobile wireless body area networks," Journal of Medical Systems, 2011, 35(5), 12771287.

[60] Khan, P., et al., "Seamless interworking architecture for WBAN in heterogeneous wireless networks with QoS guarantees," Journal of Medical Systems, 2011, 35(5), 1313-1321.

[61] Lee, K. D., and Vasilakos, A., "Access stratum resource management for reliable u-healthcare service in LTE networks," 2011, Wireless Networks, 17(7), 1667-1678.

[62] Li, C., et al., "A novel medium access control protocol with low delay and traffic adaptively for wireless body area networks," Journal of Medical Systems, 2011, 35(5), 1265-1275.

[63] Ullah, S. and Kwak, K. S., "Throughput and delay limits of IEEE 802.15.6," In: Proceedings of IEEE WCNC, 2011.

[64] Ameen, M. and Liu, J., and Kwak, K. "Security and privacy issues in wireless sensor networks for healthcare applications," Journal of Medical Systems, 2012, 36(1), 93-101.

[65] Huang, C. and Lee, D. H., "A privacy-strengthened scheme for ehealthcare monitoring system," Journal of Medical Systems, 2012, 36(5), 2959-2971.

[66] Stuart, E. and Moh, M., and Moh, T. S., "Privacy and security in biomedical applications of wireless sensor networks," In Proceedings of IEEE ISABEL, 2008, pp. 1-5.

[67] Jiang, Q., Ma, J., Ma, Z., and Li, G., "A privacy enhanced authentication scheme for telecare medical information systems," Journal of medical systems, 2013, 37:9897. 
[68] Kumari, S., Khan, M.K.,Kumar, R., "Cryptanalysis and improvement of a privacy enhanced scheme for telecare medical information systems," Journal of medical systems, 2013 37(4), Article: 9952, doi: 10.1007/s10916- 013-9952-9955,.

[69] Chen, C.L., Yang, T.T., Chiang, M.L., and Shih, T.F., "A privacy authentication scheme based on cloud for medical environment," Journal of medical systems. 38(11):1-16, 2014. Doi: 10.1007 /s10916-0140143-9.

[70] Zhou, C., and Chao, H., "Multimedia traffic security architecture for internet of things," IEEE Network, 2011, 25(3), 35-40.

[71] Selimis, G., et al., "A lightweight security scheme for wireless body area networks: Design, energy evaluation and proposed microprocessor design," Journal of Medical Systems, 2011, 35(5), 1289-1298.

[72] Seyedi, M., "A survey on intraday communications for body area network applications," IEEE Transactions on Biomedical Engineering, 2013, 60(8), 2067-2079.

[73] A. Wong, et al, "Burdett A 1 V 5 mA multimode IEEE 802.15.6/Bluetooth low-energy WBAN transceiver for biotelemetry applications," IEEE J. Solid-State Circuits, 2013, vol. 48, no. 1, pp. 186198.

[74] Riccardo Cavallari, et al, "A Survey on Wireless Body Area Networks: Technologies and Design Challenges," IEEE, 2014, 1553877X/14/\$31.00_c.

[75] H. B. Lim and D. Baumann and E.-P. Li, "A human body model for efficient numerical characterization of UWB signal propagation in wireless body area networks," IEEE Trans. Biomed. Eng., 2011, vol. 58, no. 3, pp. 689-697.

[76] K. Y. Yazdandoost and K. Sayrafian-Pour and K. Hamaguchi "RF propagation and channel modeling for UWB wearable devices," IEICE Trans. Commun, 2011, vol. E94-B, no. 5, pp. 1126-1134.

[77] J. Bae, et al, "A low-energy crystalless double-FSK sensor node transceiver for wireless body-area network," IEEE J. Solid-State Circuits, 2012, vol. 47, no. 11, pp. 2678-2692.

[78] M. Callejon, et al, "Distributed circuit modeling of galvanic and capacitive coupling for intra body communication," IEEE Trans. Biomed. Eng., 2012, vol. 59, no. 11, pp. 3263-3269.
[79] M. S. Wegmueller, et al, "Signal transmission by galvanic coupling through the human body," IEEE Trans. Instrum. Meas., 2010, vol. 59, no. 4, pp. 963-969.

[80] Golmie, N., Cypher, D., \& Re'bala, O., "Performance analysis of low rate wireless technologies for medical applications," Computer Communications, 2005, 28(10), 1266-1275.

[81] Zambrano, A. and Garcia Betances. R., "Municipal communications infrastructure for rural telemedicine in a Latin-American country," Latin America Transactions, IEEE 2012, 10(2), 1489-1495.

[82] B. S. Lin, et al, "RTWPMS: A real-time wireless physiological monitoring system," IEEE Trans. Inf. Technol. Biomed., 2006, vol. 10, no. 4, pp. 647-656.

[83] F. Felisberto, F. Fdez-Riverola, A. Pereira, "A ubiquitous and low-cost solution for movement monitoring and accident detection based on sensor fusion," 2014, Sensors 14 (5), 8961-8983.

[84] Li, H.-B., et al, "Body area network and its standardization at IEEE 802.15.MBAN," In 16th IST on mobile and wireless communications summit, Budapest, Hungary, 2007, pp. 1-5.

[85] Chen, M., et al, "Body area networks: A survey, Mobile Networks and Applications,” 2011, 16(2), 171-193.

[86] Mustafa Almahdi Algaet et al, "Provisioning Quality of Service of Wireless Telemedicine for E-Health Services: A Review," Springer Science and Business Media New York, 2014.

[87] Theogarajan, L. et al, "Minimally invasive retinal prosthesis in solidstate circuits," in the Proc. of IEEE International Conference Digest of Technical Papers, 2006, pp. 99-108.

[88] K. Jamil and Y. Mehmet, "Wireless Body Area Network for Medical Applications," New Developments in Biomedical Engineering, 2010, no. 1 , pp. 591-628.

[89] Hadjidj, A. et al, "Wireless sensor networks for rehabilitation applications: Challenges and opportunities," Journal of Network and Computer Applications, 2013, 36(1), 1-15.

[90] Peter Van Daele and Ingrid Moerman and Piet Demeester, "Wireless body area networks: status and opportunities," IEEE, 2014, 978-1-46735225-3/14/\$31.00. 